\title{
Developing design courses in a project-based curriculum
}

\section{Dr. Mohammad Habibi, Minnesota State University, Mankato}

Dr. Habibi is an assistant professor in the Department of Integrated Engineering at Minnesota State University-Mankato. He received his undergraduate and graduate degrees in Electrical Engineering. Following his postdoctoral appointments at the University of Wisconsin-Milwaukee, he joined the Iron Range Engineering (IRE) program in August 2011. The IRE is an innovative, 100\% project-based, upper division engineering program located in Virginia-Minnesota which promotes learning in the context of engineering projects, professionalism and reflection (metacognition). His research in the area of engineering education is focused on project-based learning, design and innovation, professionalism and self-directed learning.

\section{Mr. Ronald R Ulseth, Iron Range Engineering}

Ron Ulseth directs and instructs in the Iron Range Engineering program in Virginia, Minnesota and he teaches in the Itasca Community College engineering program in Grand Rapids, MN. He was instrumental in growing the Itasca program from ten students in 1992 to 160 students in 2010. In 2009, he worked with a national development team of engineering educators to develop the 100\% PBL curriculum used in the Iron Range model. He has successfully acquired and managed over \$10 million in educational grants including as PI on seven grants from NSF. He has been in the classroom, teaching more than 20 credits per year to engineering students for more than 20 years. His specific areas of expertise are in active learning, faculty development, and learning community development. He has been awarded the 2012 Progress Minnesota award, 2012 Labovitz Entrepreneurialism award, and 2012 Innovator of the Year award from the Rural Community College Alliance all for his work in developing the Iron Range Engineering program. His B.S. in Civil Engineering is from the University of North Dakota, and his M.S. in Mechanical Engineering is from the University of Central Florida. He is licensed as a professional engineer in the state of Minnesota

\section{Mr. Michael Richard Carlson}




\title{
Developing design courses in a project-based curriculum
}

\begin{abstract}
:
Iron Range Engineering program, located in northeastern Minnesota, is an innovative, completely project-based learning model where the students practice engineering before graduation. In this program, students from various upperclass levels and disciplines form a team and work on multidisciplinary projects. In an effort to improve the student experience and increase the efficiency of learning engineering design, we have developed a new method of teaching engineering design which covers most aspects of a design. The new method fits into a four- semester design course series. The new method uses project-based learning and also addresses the issue of having students from multiple upperclass levels on one team.
\end{abstract}

\section{Introduction}

Design is an important part of the engineering curricula not only in the eyes of industry but also the Accreditation Board of Engineers and Technology (ABET) ${ }^{1,2}$, therefore special attention has been given to design courses at engineering colleges across the nation and worldwide. In design courses, students integrate and apply their knowledge to design products or to address problems. The design process generally has been identified as scoping, generating, evaluating and realizing ideas; however, there are various ways of teaching engineering design. A review on the design literature is available ${ }^{3}$.

While technology advances every day, many various concepts such as economic analysis, mass production, reliability, sustainability, and contextualization have to be considered in engineering design. It has been recognized that engineering curricula and specifically, engineering design courses have not been providing adequate and proper guidance on all aspects of design to meet the needs of competitive global marketplace ${ }^{2,4}$.

Project-based programs, specifically in engineering, provide active learning environments for students to learn in the context of projects ${ }^{5,6}$. Engineering projects may be defined by faculty, industry or even students which also might be real-life engineering problems. Iron Range Engineering (IRE), as a 100\% Project-based Learning (PjBL) program, motivates learning by providing industry-defined /-mentored projects ${ }^{7,8,9}$. The IRE students complete the first two years of their program at the local community colleges and then join the program for their junior and senior years. The students must enroll and complete four design courses, each three credits, called Design I, Design II, Capstone Design I and Capstone Design II.

At IRE junior and senior students (different upperclassman levels) work closely together as a team on the same design project. In addition, students with different engineering disciplines may participate in one design project. These aspects require a design syllabus which effectively provides guidance for all students on a team. 
Recently, the IRE faculty developed a new method of teaching engineering design which fits into four design courses. In this method, students learn and practice major design components such as scoping, generating, evaluating, and realizing ideas at two introductory and advanced levels. They are also given opportunities to learn other aspects of engineering design. This method not only defines different expectations for junior and senior students, it makes the grading fair and straightforward. This paper reports the highlights of the method.

\section{Iron Range Engineering Program}

\subsection{Program history}

In the center of Minnesota's Mesabi Iron Range, an innovative, new model for engineering education has been established. At the beginning of 2010, IRE program began teaching its first generation students using a 100\% PjBL pedagogy. The model promotes self-directed learning, professionalism skills and engineering design. In this PjBL program, students work on design projects defined by industries in the area or close by. Working in close contact with industry, the IRE students are able to develop their professional skills as well as acquire technical competencies in the context of their design projects.

IRE is a two years upper-division engineering program with only juniors and seniors. Prior to the IRE program, students must have completed 68 credits worth of prerequisite courses at another college. Commonly, they are graduates of local community colleges, with the biggest enrollment from Itasca Community College in Grand Rapids, Minnesota. While attending IRE, each student must enroll and complete 60 credits in three different areas: professionalism, technical competency, and engineering design.

These 60 credits consists of eight credits electrical core, eight credits mechanical core, 16 credits technical elective, 12 credits of professionalism, 12 credits of engineering design and 4 credits of seminar. The 32 technical competencies are commonly related to the some aspects of the design project. One of the requirements for each technical competency is a deep learning activity (DLA), which is an in-depth experiment to understand a concept or process more fully. To conclude a competency, a student completes an oral exam with the instructor for an average time of one hour. In order to graduate in two years, a student needs to complete eight technical competencies per semester in addition to seven credits of professionalism, design and seminar.

IRE students must take 3 credits of design each semester and work closely with their teammates to complete their projects. With the design groups set up in a team setting allows the students to interact similar to how engineers do in industry. A distinctive feature of these design groups at IRE is that each group is not comprised of students with the same emphasis or class level. This is unique to IRE and allows each project to be worked on from many different perspectives. In each of the projects there are up to eighteen design components to be completed. At the end of a student's IRE experience, the student must have completed all eighteen design components.

After completing the IRE curriculum of 60 credits, a student will graduate with a Bachelor of Science degree in general engineering and possibly an emphasis in their area of study from Minnesota State University, Mankato. The emphasis for each student is different depending on the type of technical competencies complete. A student must complete 12 credits of their elective competencies in a specific discipline to receive an emphasis. The emphases include mechanical, 
electrical, biomedical, process engineering, etc.

\subsection{Projects}

There are generally three types of design projects at IRE: industry sponsored/mentored, entrepreneurial and co-op projects. These projects are commonly multidisciplinary projects. Industry projects form more than $80 \%$ of total and are proposed by local industries. These types of projects are open-ended, real-world engineering problems initiated from industries who are seeking the best solutions to their current engineering problems. One example from spring 2012 would be the design of a power substation for ESSAR Steel Minnesota. The project consisted of detailed design of structural and foundation, wall and roof construction, heating and ventilation, cooling, electrical fault analysis, grounding system, electrical equipment layout, and cable-tray in design accordance to all codes and regulations.

The second types of projects are proposed by the IRE students or faculty. Traditionally, the IRE students work on these types of projects in their first semester at IRE. An example of this type of projects is the design of a new Tesla-generator. In this project, students developed a new generator based on the combination of a Tesla turbine and a pulse- jet engine. The prototype was successfully tested to prove the concept stage. Since we have a few co-ops or interns working part-time for local companies, they propose their current work at the company as a project. These students follow the same design process except that they benefit greatly from external mentors.

\subsection{Project teams}

At the conclusion of each semester, the students are asked about the types of projects they would like to work on in the following semester. Some of the types pursued by the IRE students include: mechanical, electrical, industrial, and biomedical. After a list of the different types has been formed, the program requests industry partners to propose projects preferably related to the topics requested. Once all the projects for the next semester have been finalized, a menu is generated. Each student in the program may select up to three projects from the menu based on his/her interests. Students are usually given their first or second choice.

Each project team consists of three to six students depending on the complexity of design and a faculty member as a mentor. The mentor for each team attends the design reviews held each week to monitor the progress of the project, and to help with any complications in the design process. The team members include students from all different emphases and also students of different upperclass levels. In order to allow juniors and seniors to be involved on the same project, a separate syllabus is set up for each upperclass level. Four different design courses compose the design curriculum for each student at IRE and are labeled as Junior Design I, Junior Design II, Capstone Design I, and Capstone Design II. To graduate a student is required to complete each aspect of the design process. Table 1 describes design components and project assignments to be completed in a student's junior or senior year. Each student must complete the individual score card prior to the graduation. 
Table1. Individual Design Score Card (S: Senior, J: Junior)

\begin{tabular}{|l|l|l|l|l|l|}
\hline Design Components & Year & $\begin{array}{l}\text { First } \\
\text { Semester }\end{array}$ & $\begin{array}{l}\text { Second } \\
\text { Semester }\end{array}$ & $\begin{array}{l}\text { Third } \\
\text { Semester }\end{array}$ & $\begin{array}{l}\text { Fourth } \\
\text { Semester }\end{array}$ \\
\hline Scoping I & J & & & & \\
\hline Scoping II & S & & & & \\
\hline Background Survey I & J & & & & \\
\hline Background Survey II & S & & & & \\
\hline Options I & J & & & & \\
\hline Options II & S & & & & \\
\hline Experiment Design I & J & & & & \\
\hline Experiment Design II & S & & & & \\
\hline Patent Search & J & & & & \\
\hline Economic Analysis & J & & & & \\
\hline Mass Production & J & & & & \\
\hline Engineering Standard & S & & & & \\
\hline Physical Modeling & J & & & & \\
\hline Computer Simulations & S & & & & \\
\hline Applied Science & J & & & & \\
\hline Validation and Verification & S & & & & \\
\hline Reliability & J & & & & \\
\hline Sustainability Analysis & J & & & & \\
\hline Project Management & S & & & & \\
\hline Design improvements & S & & & & \\
\hline Statistical Analysis & S & & & & \\
\hline Contextualization & S & & & & \\
\hline
\end{tabular}

\subsection{Deliverables}

There are typically two types of deliverables: IRE and client's deliverables. The IRE deliverables include three presentations (scoping, progress and final design review), final technical report, and a number of documents associated with the design. The final technical report contains all the design documents that students develop during the semester plus a section about their technical and teamwork learning achievements. Client's deliverables depend on the nature of project and client's preferences. In most cases, it includes the detail of design, information gathered from vendors, economic analysis report, experiment report, possibly a prototype and any document that helps the client finalize the decisions. Students are required to present the final design to their client at the end of semester.

\section{Design syllabus}

\subsection{Course Description}

Junior Design I, II are the design courses in IRE students' first and second semesters. The overarching goal of this semester is to become acquainted with project-based learning by being guided through the IRE design cycle. In addition to basic design components such as scoping, background survey, options selection, and experiment design at an introductory level, each student learns, and practices, some of design components such as patent search, mass production, reliability calculations, economic analysis, applied sciences, physical modeling and sustainability. The selection of each component is based on the project, student's choice and the mentor recommendation. Typically, first semester students do not have an external client, leaving the acquisition of client interaction skills for the second semester. The primary goal of 
the second semester is to become proficient in managing a design project, client interactions, team interactions and personal learning. Mentors provide substantial scaffolding during the second semester as these proficiencies are gained. Upon successful completion of Junior Design courses students are ready for the major capstone experiences in their senior year.

Capstone Design I, II are the design courses in IRE students' third and fourth semesters. The purpose of the capstone experience is to incorporate the vast set of technical, professional, and design experiences from earlier design course work into a major design experience that are expected in engineering practice after graduation. The senior students may perform the basic design components such as scoping, background survey, options selection, experiment design at an advanced level. They also learn and practice components of the design such as engineering standards, design process/improvements, statistical analysis, contextualization, computer simulation, verification \& validation, contextualization and project management. The selection of each component is based on the team project, student's choice, and mentor recommendation. The capstone experience may be for an industry client, entrepreneurial in nature, or some other significant design project determined by the faculty or students. The faculty expects a high level of student performances as project managers, engineering designers, and technical professionals.

\subsection{Desired learning outcomes}

Desired learning outcome are defined based on ABET student outcomes. There are a number of ABET outcomes associated with the design course sequence as follows:

The IRE students are required to apply engineering principals to achieve the best solutions that meet desire needs of their project (Outcome A). The students must design and conduct experiments to gain required knowledge of their project or to prove that their solution meet the needs of project. (Outcome B). These experiments usually involve using modern engineering tools and techniques (Outcome K). Each project is involved in design a system, prototype, components or a process to address an engineering problem (Outcome $\mathrm{C}$ ). The projects are mostly multidisciplinary (occasionally single-discipline) and the students with different backgrounds form a team to work on their project (Outcome D).

The first phase of each project is to understand, formulate the problem and the second phase is to propose solutions. All IRE students are required to complete these two phases (Outcome E). A big portion of project deliverables is three to four presentations and final technical report. After each presentation, the students are given feedback from all faculty and peers regarding both presentation and technical writing skills. Each section of their final technical report is reviewed and graded by a different instructor (Outcome $\mathrm{G}$ ). One of the deliverables of each project is a contextualization document which reports what significance the final design may have on the environment, global, health, safety, economics, ethics, etcetera (Outcome H). Another deliverable is a report on project management. Students are required to manage all aspect of their projects and submit the project management document describing how they managed their project including project planning, budgeting, scheduling, execution, managing the available resources, monitoring and controlling the project (Outcome L).

Lastly, students are engaged in entrepreneurial projects for at least their first semester (Outcome M). They are required to recognize the business potential of an idea and identify a potential market, and then assess market potential of a product. Based on their technical evidence and 
submitted documents, these outcomes are evaluated and IRE faculty make sure that every student achieves these outcome before graduation.

\subsection{Description of Design Components}

Scoping I - The scoping document and presentation should describe the scale of the project including the work that needs to be performed in order to deliver the product. It should summarize meetings with the project client and discuss their expectations, deliverables, time lines, and any other possible considerations that have been made.

Scoping II - In addition to the requirements described in Scoping I, senior students should consider a broader scope than just client's needs and preferences. In addition to excellent technical writing and well-defined project approaches, students must describe reachable goals and objectives.

Background Survey I - This document should summarize a review of available information from various sources including online materials, experts' notes or work done at IRE related to the project. It should also include a review on available technologies that can be applied throughout the project while taking into account existing patents.

Background Survey II - In addition to the expectations of Background Survey I, senior students should use more reliable, relatively new sources of information such as books or academic papers. The document must be well-written with no or minimal errors. The full citation must appear at the end of document using one of the commonly used citing methods.

Options I - The options document must describe all the possible solutions to the project that the team brainstormed or investigated. Some of the options should reflect the benchmarking that was performed in the research paper. An evaluation of the options should also be included.

Options II- In addition to the expectations of Options I, senior students are expected to break the project into small parts and consider as many options as possible. They should also use advanced techniques such as Decision Matrices to skillfully propose suitable options. Each option must be professionally and scientifically weighted.

Experiment Design I- While working on the design project, junior students are expected to design and conduct experiments and analyze the results. The experiment should be at least partially related to the design project. The document should include experiment procedure, results and conclusions.

Experiment Design II- In addition to the expectations of Experiment Design I, senior students must design experiments that considerably contribute to the project. The document must contain significant data analysis and be well-written.

Patent Search- The patent search document describes all directly and indirectly related patents to the project. It also should offer estimates of value and royalty rates of related patents. 
Economic Analysis- This document should cover financial and economic decision-making for engineering aspects of the project. It should emphasize problem solving, life-cycle costs, and the time value of money consideration. Additionally, it should address the client's concerns regarding all direct and hidden costs of the project. Elements to consider include overall business case, design costs, manufacturing costs, operating costs, maintenance, selling price, total market, percentage of market captured, warranty costs and disposal costs.

Mass Production- If the design project is a product, this document should describe the cost and method of producing the product in large quantities at low cost per unit. If the project is a solution to a problem, the document should address how the team can sell the solution nationally and internationally.

Engineering Standards- In this document, students should address all engineering standards, codes and regulation related to the project including safety concerns, health, environment, government permits, etc.

Applied Science (math modeling) - This document must describe the process of applying science, engineering, and mathematical knowledge in the design project. This document should also contain necessary equations and calculations.

Computer Simulation- Computer simulation is an advance mathematical modeling of the design where the team uses computer programming to model the design project or a portion of it.

Validations and Verifications- This document must describe procedures used to check if the product/solution fulfills its intended purpose and meets its requirements/ specifications.

Reliability- This document must include the calculation of time period which the product or design is expected by its designers to work within its specified parameters. Reliability is an important concept because industry is rapidly moving to understand a complete product life cycle cost versus traditional shorter-term strategies.

Sustainability- This document must summarize the life cycle availability of resources including components, manufacturing processes, and supply chain which affects the sustainability of the design project.

Project Management- This document should describe how the team manages the design project which may include project planning, budgeting, scheduling, executing, managing the available resources, monitoring and controlling the project. Using project management software is strongly recommended.

Design Process \& Improvements- This report must contain the design concepts initially developed and the process used to improve the design. Future improvements on design must be included.

Contextualization- Determines what significance your final recommendation may have on the environment, health, safety, economics, ethics, and social. 
Physical modeling- This task requires students to build a physical, non-functional model which helps them visualize the project in three dimensions.

Statistical analysis- Students are required to perform advanced data analysis using statistical analysis techniques. Uncertainties or confidence level in the experiment must be identified and calculated. The document must also present the statistical relationships between measured values and the model.

Teamwork achieved- This document should cover the quality of individual and group teamwork learning, teamwork achieved assessment processes and the areas for team improvement.

\subsection{Deliverables and Grading}

For each student at IRE, the design grade is consisted of one hundred points which are equally distributed between individual and team deliverables. The team decides which of the design components are applicable to the project at the first design review meeting with the team mentor. After deciding the design components, applicable to the project, each team member selects five design components to be the author or co-author of. Each paper is worth ten points. These design component papers are the fifty points that comprise the individual design grade.

The other half of the design grade is dependent on the team performance in different areas such as multiple presentations during the semester, final technical report and client's deliverables. Each team has to present to the IRE community the scope, progress, and final status of the project. The presentations are graded on both presenting skills and technical aspects. Each presentation is worth five points of the team deliverables. The final technical document is the complete arrangement of all design components completed by the team. Each individually completed document is altered from a standalone paper to a complete flowing final technical report. This final technical report comprises twenty five points of the design grade.

The final aspect of the design grade is the client deliverables. The client deliverables depend on the scope of the project; for example they can be final drawings of a designed building or an apparatus. For the smaller scale projects, a working prototype is expected to be the final client deliverable. In both large and small scale projects a technical document is presented to the client with all the technical detail of design. The client is requested to grade the final deliverable from the team and gives the team a grade from one to ten; these are the last ten points of the team's design grade.

\section{Students' perceptions of the syllabus}

Continuous improvement in all aspects is the main focus of the program. To understand if the design syllabus is adequate for the different design projects, a survey was designed and conducted to receive the students' perception of the design syllabus. The questions asked in the survey included:

1. Which rubric, deliverable, design component is unclear and how would you suggest we improve it?

2. Should there be any more design components added to the syllabus?

3. Are there any unimportant design components which should be deleted from the syllabus? 
4. What do you think of grading, any idea to improve it?

5. If you have completed a project interning or in a co-op, how did the process compared to IRE design process? Was your boss pleased with how you completed it or did he want more/less?

6. Which part of syllabus needs improvement and how we improve it?

Most of the students believed that design syllabus is very effective and contain adequate design components. The students also believed that some of the design components are unclear on the syllabus and suggested that workshops or talks can help clarify them. They also suggested that few design components such as Background Survey \& Patent Search, Statistical Analysis \& Experiment, Economic Analysis \& Mass Production and Reliability \& Sustainability Analysis could be combined. An additional comment was that the grading was confusing if a senior and a junior work on the same paper. These comments will be implemented in the new improved version of syllabus for spring 2013.

\section{References}

1. Wilczynski, V., Douglas, M., (1995) " Integrating Design Across the Engineering Curriculum: A Report From the Trenches," Journal of Engineering Education, v84 n3 p235-40

2. Nicolai, L.M., (1998) "Viewpoint: An Industry View of Engineering Design Education, Int. J. Engineering Education, 14: 7-13.

3. Libii J. N., (2003), “ Integrating of design in the engineering core: Teaching engineering science with design in mind," Proceedings 2012 ASEE Annual Conference, AC 2003-3125

4. Sheppard K., Gallois B.,(1999) "The Design Spine: Revision of the Engineering Curriculum to Include a Design Experience each Semester,” Proceedings 1999 ASEE Annual Conference, Session \#3225

5. Thomas, J.W. 2000. A review of research on project-based learning. San Rafael, CA: Autodesk Foundation.

6. Dutson, A. J. Todd, R. H. Magleby, S. P. Sorensen, C. D. (1997), “A Review of Literature on Teaching Engineering Design Through Project Oriented Capstone Courses" Journal of Engineering Education. VOL 86; NUMBER 1, pages 17-28

7. Habibi M., Ulseth R. (2012), “Time allocation Scaffolding in Project-Based Learning” Proceedings 2012 ASEE Annual Conference, AC 2012-4180

8. Ewart D., et al, (2011) "Entrepreneurship in the Iron Range Engineering (IRE) Model," Proceedings 2012 ASEE Annual Conference, AC 2011-974

9. Kilpatrick E., Stage E. (2012), "Self-motivated Learning for Professionalism in an Immersive Learning Model," Proceedings 2012 ASEE Annual Conference, AC 2012-4976 